\title{
Uma análise do curta "Menina bonita do laço de fita": os efeitos de sentido das múltiplas linguagens do gênero videoanimação
}

DOI: http://dx.doi.org/10.21165/el.v50i2.2963

\author{
Jaciluz Dias ${ }^{1}$ \\ Marta Cristina da Silva ${ }^{2}$
}

\section{Resumo}

O objetivo deste artigo é apresentar uma possibilidade de análise para a videoanimação Menina bonita do laço de fita (2014), tendo em vista as linguagens verbal, visual e sonora que compõem esse texto multimodal. Para tanto, adotamos como procedimento metodológico um levantamento bibliográfico e webliográfico, que apoia a análise da videoanimação nos pressupostos da Gramática do Design Visual (KRESS; VAN LEEUWEN, 2006), dos 12 Princípios da Animação da Disney (THOMAS; JOHNSTON, 1995) e em concepções sobre as vozes, as músicas e os efeitos sonoros (FURNISS, 2014). Dessa forma, chegamos a considerações que demonstram como essa abordagem pode não só contribuir para o ensino de língua portuguesa, mas também tratar de temas atuais, como o combate ao racismo e a valorização da identidade negra.

Palavras-chave: Multiletramentos; gênero videoanimação; Gramática do Design Visual; 12 Princípios da Animação.

\footnotetext{
1 Universidade Federal de Juiz de Fora (UFJF), Juiz de Fora, Minas Gerais, Brasil; jaciluzdias@gmail.com; http://orcid.org/0000-0002-0699-921X

2 Universidade Federal de Juiz de Fora (UFJF), Juiz de Fora, Minas Gerais, Brasil; martacris.silva@gmail.com; https://orcid.org/0000-0003-1917-1734
} 


\title{
An analysis of the short film Nina Bonita: the meaning effects generated by the multiple languages of the animation genre
}

\begin{abstract}
This paper aims to present a possibility of analysis for the animated short film Nina Bonita (2014), considering the verbal, visual, and sound languages that make up this multimodal text. To do that, we have assumed as a methodological procedure some bibliographical and web research, which supports the analysis of the short film according to the principles of The Grammar of Visual Design (KRESS; VAN LEEUWEN, 2006), Disney's 12 principles of animation (THOMAS; JOHNSTON, 1995), and conceptions about voices, songs, and sound effects (FURNISS, 2014). Thus, we come to conclusions that show how this approach may not only contribute to the teaching of Portuguese but also deal with current subjects, such as the struggle against racism and the valorization of black identity.
\end{abstract}

Keywords: Multiliteracies; the animated short film genre; The Grammar of Visual Design; 12 Animation Principles.

\section{Introdução ${ }^{3}$}

Pesquisadores na área da educação concordam sobre a relevância de se explorar gêneros multimodais em ambiente digital no processo de ensino-aprendizagem de língua. Mas de que modo um gênero como a videoanimação poderia contribuir para a formação de leitores e produtores de textos mais críticos e sensíveis a pautas importantes da contemporaneidade como o racismo? Se combater o racismo é responsabilidade de todas as pessoas que formam uma sociedade, isso tem-se evidenciado com as recentes manifestações de movimentos como o Black Lives Matter, nos Estados Unidos, que buscam visibilidade para os assassinatos e a discriminação de pessoas negras. No Brasil os problemas não são diferentes, e, conforme defende Djamila Ribeiro (2019), práticas antirracistas são fundamentais e precisam acontecer nas atitudes mais cotidianas.

Nesse contexto, sabendo-se da importância da educação para a transformação social, buscamos apresentar uma possibilidade de análise de Menina bonita do laço de fita (2014), considerando as linguagens verbal, visual e sonora que compõem essa videoanimação.

3 Sabemos que, conforme apontamentos de alguns autores, como Dionísio (2007, p. 177), todo texto pode ser considerado multimodal, já que, "quando falamos ou escrevemos um texto, usamos, no mínimo, dois modos de representação: palavras e gestos, palavras e entonações, palavras e imagens, palavras e tipografia, palavras e sorrisos, palavras e animações, etc.". Porém, neste trabalho, buscamos destacar as múltiplas linguagens (imagens estáticas e em movimento, sons, gestos etc.) presentes em textos contemporâneos, mais especificamente os digitais, os quais, em consonância com a proposta de Rojo (2014), são denominados textos multimodais ou multissemióticos. 
Esse texto digital pode contribuir para o ensino de língua portuguesa em sentido amplo, possibilitando o trabalho, por exemplo, sobre textos literários e relações intertextuais, bem como o enfoque em temas relacionados à identidade negra e representatividade. Para isso, utilizamos como procedimento metodológico um levantamento bibliográfico e webliográfico que apoia a análise da videoanimação, a partir dos pressupostos da Gramática do Design Visual - GDV, elaborada por Kress e van Leeuwen (2006), como metodologia de análise para textos multimodais. Recorremos, ainda, aos 12 Princípios da Animação da Disney, organizados por Frank Thomas e Ollie Johnston (1995), que permitem um olhar mais aprofundado sobre os elementos dos desenhos em movimento. Esses autores ainda contribuem para a análise da sonoplastia das animações, a cujo referencial somam-se as concepções de Maureen Furniss (2014), que discorre sobre as vozes, as músicas e os efeitos sonoros de animações.

Tendo em vista que os documentos oficiais norteadores dos caminhos do currículo escolar brasileiro, como a Base Nacional Comum Curricular - BNCC (BRASIL, 2018), sinalizam a necessidade de incluir as tecnologias digitais e os textos multimodais sobre temas atuais e necessários à cidadania, procuramos demonstrar, nos resultados, que o gênero videoanimação pode contribuir para o ensino de língua portuguesa. Buscamos, então, dar ao professor ferramentas para o trabalho com os multiletramentos, a fim de despertar nos alunos um senso mais crítico diante da realidade.

\section{A Gramática do Design Visual (GDV) como metodologia de leitura}

A fim de compreender melhor a representação não verbal como parte da comunicação humana, Kress e van Leeuwen (2006, p. 20) desenvolveram uma metodologia de análise denominada Gramática do Design Visual (GDV), por entenderem que as imagens assumem "não apenas as dimensões estéticas e expressivas, mas também as dimensões sociais, políticas e comunicativas estruturadas" (KRESS; VAN LEEUWEN, 2006, p. 20, tradução nossa ${ }^{4}$ ). Para esses autores, assim como o conhecimento de outros idiomas permite novas abordagens no âmbito da língua, o conhecimento de diferentes modos semióticos, para além do verbal, pode ampliar as perspectivas de uso da linguagem.

A GDV parte da noção de que aquilo que pode ser expresso em palavras também pode ser expresso por meio de imagens. Porém, não sem que haja algumas diferenças no que se refere aos processos de significação. No complexo processo comunicacional, a compreensão de um texto depende não apenas da decodificação do código verbal de uma língua, sendo influenciada, também, pelas interações sociais, que são determinantes para a organização da linguagem. Essa dimensão interpretativa aumenta, significativamente, quando são utilizadas imagens. Isso porque a linguagem, seja verbal, seja não verbal,

4 No original: "not only the aesthetic and expressive, but also the structured social, political and communicative dimensions". 
baseia-se em signos e nas relações decorrentes de significantes e significados culturalmente estabelecidos. Nesse sentido, Kress e van Leeuwen (2006) defendem que as escolas precisam repensar o que deverá ser incluído nos currículos, considerando o crescente número e o uso cada vez mais difundido de textos multimodais, inclusive pelo fato de esse processo interferir nos usos da escrita, bem como nos novos arranjos entre as linguagens verbal e não verbal. Assim, os educadores precisam ser capazes de equipar os alunos para uma nova ordem semiótica, a fim de contribuir para a formação de indivíduos capazes de usar os novos recursos de representação de maneira ativa e eficaz.

A GDV é proposta, então, como forma de metodologia para auxiliar nessa nova configuração. Decorrente da Gramática Sistêmico Funcional (GSF), de Halliday (1994), a GDV busca estabelecer categorias gerais e abstratas para todos os tipos de semiose humana. Kress e van Leeuwen (2006) partem dessas metafunções propostas pela GSF e, considerando a perspectiva multimodal, a GDV renomeia essas metafunções como: representacionais (ideacional na GSF), que tratam das experiências do mundo por meio da linguagem; interativas (interpessoal na GSF), que analisam as estratégias para aproximação e afastamento do leitor; e composicionais (textual na GSF), que enfocam a organização interna dos elementos no texto.

A compreensão das metafunções ${ }^{5}$ requer, antes, que sejam apresentados os elementos envolvidos na cena comunicativa ou ato semiótico. Eles podem ser o Participante Interativo (PI deste ponto em diante), as pessoas reais (produtores e consumidores da imagem), ou o Participante Representado (PR deste ponto em diante), que corresponde a tudo o que está na imagem (pessoas, lugares, objetos etc.). Os efeitos de sentido da imagem, organizados por meio das três metafunções supramencionadas, decorrem das possíveis relações estabelecidas entre os PI, destes com os PR e entre os PR, conforme será demonstrado.

A metafunção representacional envolve o que está sendo representado na cena, as relações estabelecidas por esses elementos e em quais circunstâncias. A representação na imagem pode ser narrativa ou conceitual, sendo que, como Kress e van Leeuwen (2006) explicam, uma imagem pode apresentar mais de um processo simultaneamente. A representação narrativa exprime um movimento dentro da imagem, envolvendo eventos, ações e processos de mudança. Para isso, é necessário conhecer três elementos: o ator, como é chamado o PR que desempenha a ação; o vetor, o sentido da ação, que é representado por uma seta; e a meta, que é para onde o vetor indica.

5 Devido ao espaço reduzido, serão enfocados apenas os elementos utilizados para a análise da videoanimação que compõe o corpus deste artigo. Para conhecer em detalhes a GDV, conferir Kress e van Leeuwen (2006) e seus seguidores. 
Esse tipo de representação pode envolver processos ou circunstâncias. Os processos podem ser de ação, de reação, verbal, mental, de conversão ou de simbolismo geométrico. O processo de ação acontece quando há um ato desempenhado por um dos PR, uma ação física no mundo material, podendo ser não transacional ou transacional. O processo de ação transacional reúne pelo menos dois PR, sendo que ambos podem ser vistos na imagem. O processo de ação não transacional é aquele em que, na cena, aparece apenas um $P R$, que será o ator, sendo que a meta não se encontra presente na imagem, porque a ação de um PR não é direcionada a outro. Mas pode acontecer, ainda, de o PR ser representado apenas em parte, por meio de uma mão ou um pé, por exemplo, ou nem aparecer, sendo visível no ato semiótico apenas o vetor e a meta, ao que Kress e van Leeuwen (2006) denominam representação de evento.

O processo narrativo de reação ocorre quando a "ação" se manifesta por meio do olhar de um PR para outro (LEAL, 2011), sendo o vetor formado pela direção do olhar do PR para algo ou alguém. O PR que olha é denominado reator, que reage a um fenômeno, algo ou alguém que é observado (enquanto o processo de ação envolve um ator e meta). Nesse sentido, o reator deve necessariamente ser humano ou um ser humanizado, com rosto e olhos capazes de transmitir uma expressão facial. Assim como o processo de ação, o de reação pode ser transacional, quando o olhar do PR se dirige ao fenômeno, que aparece na imagem; ou não transacional, quando o olhar do PR se dirige a algo fora da imagem, um fenômeno que não aparece na imagem, para o qual o participante está olhando. Já o processo mental acontece quando há balões de pensamento ou conteúdos de processos mentais, internos, como sentimentos. Nesse caso, acontece um processo mental, realizado pelo participante que pensa, em relação a um fenômeno, aquilo que é pensado.

Nas representações narrativas, podem aparecer, ainda, elementos chamados por Kress e van Leeuwen (2006) de participantes secundários, os quais não entram na estrutura principal do ato semiótico, mas contribuem para adicionar informações. Eles não estabelecem relação direta com os participantes principais, por meio de vetores, mas indicam referências espaciais e temporais, dividindo-se em três tipos: cenário, significação e acompanhamento. A circunstância de significação reúne ferramentas utilizadas nos processos de ação, permitindo que estes sejam realizados (LEAL, 2011), mas cuja significação fica subentendida, como os gestos que complementam a fala de uma pessoa, por exemplo.

A metafunção interativa observa a aproximação entre PR e $\mathrm{Pl}^{6}$, indicando as relações estabelecidas entre os elementos da imagem e a visão de mundo dos produtores

6 Conforme explicado anteriormente, o PI pode ser quem vê a imagem ou quem a produz. Como a maior parte das relações semióticas analisadas pela GDV se referem a quem vê a imagem, a partir deste momento, passa-se a identificar o PI que vê a imagem apenas como PI, diferenciando-o do PI produtor quando necessário. 
desta, ou seja, os valores que se pretende transmitir por meio do ato semiótico. Essa metafunção trata, então, especificamente da interação entre os PR, entre PI e PR e entre os PI, dividindo-se em três abordagens: o olhar, o enquadramento e a perspectiva. Uma das formas de interação pode ser estabelecida por meio do olhar, que estabelece uma relação entre PR e PI, a qual pode ser de dois tipos: demanda ou interpelação e oferta ou exposição. O olhar de demanda acontece quando o PR olha diretamente para o PI, o que pode demonstrar que o PI produtor quer criar um vínculo emocional entre PR e PI. Já, no olhar de oferta, o PR se dirige ao PI de forma indireta, não olhando para ele, mas sendo objeto de seu olhar.

A forma como a cena é enquadrada indica maior ou menor proximidade entre PR e PI, conforme os planos utilizados pelo cinema: desde o plano fechado (ou close-up), que enquadra o rosto ou um detalhe do PR e indica maior proximidade, passando pelo plano médio, que enquadra o PR à distância intermediária, até o plano geral, que enquadra um ou mais PR à maior distância, demonstrando menor proximidade com o PI. A perspectiva é uma noção utilizada em obras de arte desde o Renascimento (BRITO; PIMENTA, 2009) e envolve o ângulo como o PR é visto pelo PI, podendo demonstrar uma atitude objetiva ou subjetiva. A perspectiva objetiva mostra tudo o que precisa ser revelado ou tudo o que o PI produtor julga necessário mostrar no ato semiótico.

Já na perspectiva subjetiva, ao contrário, revela-se o PR sob um ponto de vista específico, o que também contribui para os diferentes graus de envolvimento entre PR e PI. Essa relação é estabelecida por meio de ângulos, que podem ser dos tipos: frontal, oblíquo ou vertical. Por meio do ângulo frontal, o PI vê o PR de frente, o que denota proximidade e igualdade. O ângulo oblíquo, ao contrário, mostra o PR como se o PI não estivesse defronte a ele, o que indica distanciamento. Nesse caso, pode haver outras referências também, como o PR de costas para o Pl, o que também contribui para a noção de afastamento. O ângulo vertical é utilizado para demonstrar relações de poder entre PI e PR, que pode ser visto em ângulo alto, médio ou baixo. O ângulo alto (ou plongée, em terminologia do cinema) mostra o PR visto de cima, o que demonstra maior poder do PI em relação ao PR. O ângulo médio mostra o PR no mesmo nível de olhar, o que indica igualdade entre os participantes. E o ângulo baixo (ou contra-plongée) mostra o PR visto de baixo, o que demonstra maior poder do PR em relação ao $\mathrm{PI}$.

A modalidade é essencial para todo processo comunicativo, pois, como explica Leal (2011, p. 195), ela está "associada com a confiabilidade das mensagens. Isto é, com aquilo que o sujeito-enunciador acredita ser verdadeiro ou falso". Nesse sentido, Brito e Pimenta (2009, p. 101) lembram que o termo "vem da linguística e se refere à forma como uma oração pode ter maior ou menor grau de verdade ou credibilidade em uma determinada situação". Por isso, esse é um recurso que transita entre as três metafunções, estabelecendo as conexões entre elas. Kress e van Leeuwen (2006) abordam as modalizações à parte, mas, para tornar mais didática a organização da análise a partir da GDV, escolheu-se 
incluir esse elemento como parte da metafunção interativa, de acordo com a perspectiva adotada pelas autoras supramencionadas.

Nesse sentido, a modalidade de uma imagem pode ser elaborada por meio de marcadores, os quais são classificados em seis tipos: cor, contextualização, representação, profundidade, iluminação e brilho. A cor pode variar pelo grau de saturação (de cor plena a ausência de cor - preto e branco), diferenciação (de cores variadas a tons monocromáticos) e modulação (de sombras a cores plenas). A contextualização vai da ausência de um cenário ou fundo (background) a um cenário articulado e com muitos detalhes. A representação vai da abstração máxima até a representação realística. A profundidade varia entre a ausência de perspectiva até seu uso completo. A iluminação vai do uso de uma grande iluminação até a ausência total de claridade. E o brilho pode passar do número máximo de tons em diferentes gradações até dois tons (preto e branco, cinza claro e cinza escuro etc.).

Há diferentes tipos de modalidade, que são utilizadas conforme o propósito que se pretende para a imagem. Ela pode ser: I - naturalística, o que acontece em uma imagem que se pretende o mais próximo de como ela seria vista ao vivo, como em uma foto jornalística, por exemplo; II - abstrata, apresentando apenas o que é essencial para o reconhecimento da imagem, sem detalhamento, como em um ícone representando uma casa, por exemplo; III - tecnológica, voltada para o uso prático e explicativo, como em mapas e plantas baixas; e IV - sensorial, uma representação baseada no efeito de prazer ou desprazer que se pretende causar no PI, como em uma pintura, por exemplo.

A metafunção composicional, integrando os significados das metafunções representacional e interativa, procura analisar a forma como os elementos, tanto verbais quanto não verbais, são organizados e se relacionam no ato semiótico, e quais efeitos de sentido decorrem dessa combinação. Para tanto, são analisados três sistemas, que estão inter-relacionados: o valor informacional, a saliência e a moldura. O valor informacional relaciona-se ao layout da imagem, no que se refere à distribuição dos PR, conforme esquema (Figura 1) proposto por Kress e van Leeuwen (2006), considerando o sentido de leitura ocidental. Na imagem, organizou-se por cor e tipografia (caixa alta e caixa baixa) os aspectos correlacionados, a fim de facilitar a diferenciação e localização das informações. 
Figura 1. Valor informacional em uma imagem, de acordo com o padrão de leitura ocidental

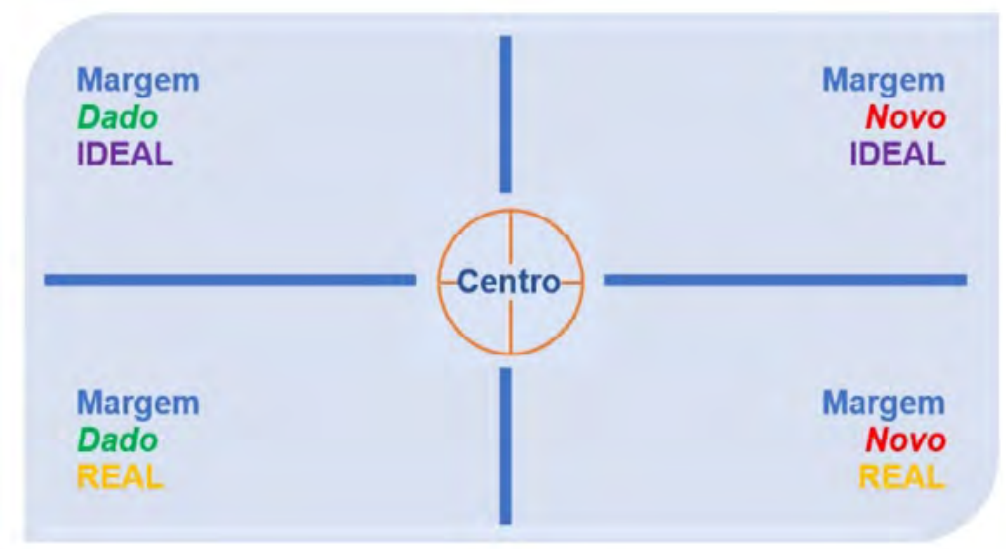

Fonte: Elaboração própria, a partir de Kress e van Leeuwen (2006, p. 197)

Dessa forma, são estabelecidos graus de importância (em azul e caixa baixa), de tal modo que a informação pode estar centrada e, portanto, ter mais destaque que os elementos dispostos nas margens, também chamados de polarizados, os quais poderão denotar dois tipos de relação. A primeira, de ordem horizontal (em verde e vermelho, caixa baixa), indica dado $X$ novo, de tal modo que aquilo que está representado à esquerda é uma informação já conhecida pelo $\mathrm{Pl}$, enquanto o que está à direita é novidade. A segunda, de ordem vertical (em roxo e amarelo, caixa alta), indica ideal $X$ real, ou seja, na parte superior o que busca estabelecer maior afinidade emotiva com o PI, aquilo que está no campo do sonho, do imaginário, e, na parte inferior, o que pertence ao campo do concreto, do mundo real.

A saliência é uma categoria de análise relacionada à forma como os PR recebem destaque no ato semiótico uns em relação aos outros, indo da máxima à mínima, o que pode ser conferido: pelo tamanho (quanto maior, mais destaque); pelo foco (a precisão de detalhes representados); pelo contraste de tons (por meio de cor e brilho); pela perspectiva (em primeiro plano o que tem mais destaque); pelo posicionamento do campo de visão (conforme os ângulos supramencionados); e por fatores culturais que revelam valores simbólicos socialmente convencionados. Por meio de composição de molduras, os PR podem passar de uma desconexão completa até uma máxima conexão, de acordo com as formas como os elementos do ato semiótico são delimitados por linhas divisórias, espaços coloridos, entre outros. Feita essa síntese sobre alguns elementos da GDV que consideramos fundamentais para a compreensão da videoanimação, e dada a especificidade desse gênero aqui focalizado, tomamos também como embasamento teórico os 12 Princípios da Animação da Disney e as contribuições de Furniss (2014) sobre recursos sonoros. 


\section{Os 12 Princípios da Animação e a sonoplastia}

Conforme explica Leticia Sato (2015), os 12 princípios são atributos que deviam ser adotados pelos animadores dos estúdios Disney, a fim de conferir o estilo estético e de movimento que, somados a outras características da animação, como a sonoplastia, configuram um estilo específico de narrar e de desenhar que constituem o padrão de qualidade da Disney. O objetivo dessas técnicas é extrair o melhor de cada desenho, em cada cena, para expressar aquilo que se pretende com a animação. Para isso, esses princípios são inspirados em movimentos do mundo real, garantindo a maior veracidade possível ao que está desenhado e, assim, conectando ficção e realidade. Isso é feito por meio de uma aproximação com as leis da física do planeta, já que, mesmo quando há cenas que se baseiam em fantasia, elas são plausíveis à realidade conhecida.

Esses parâmetros são próprios do estilo Disney de animação, existindo outras técnicas possíveis. Mas os da Disney são uma abordagem que se considera ampla e aplicável à teoria que se pretendeu desenvolver nesta pesquisa. Destaca-se, ainda, que, em uma animação, os princípios são combinados ao longo da narrativa, para provocar os efeitos de sentido desejados. São eles?: 1. Achatar e Esticar; 2. Antecipação; 3. Composição de cena; 4. Ação quadro a quadro e Ação pose a pose; 5. Movimento residual e Movimento em ondas; 6. Aceleração e Desaceleração; 7. Arcos; 8. Ação secundária; 9. Sincronia; 10. Exagero; 11. Solidez do desenho; 12. Apelo (THOMAS; JOHNSTON, 1995, p. 47, tradução nossa ${ }^{8}$. Ao longo da apresentação dos princípios que se aplicam à videoanimação analisada, procuraremos estabelecer uma aproximação entre eles e os elementos da GDV, de acordo com a abordagem descritiva que propomos neste texto.

Considerando apenas os princípios que utilizamos para a análise de Menina... (2014), começamos pelo princípio da Antecipação, que consiste em uma sequência planejada de atos que indiquem qual ação deve ser esperada. Assim, o público sabe o que acontecerá e espera que aconteça, tendo, dessa forma, prendida a sua atenção. A antecipação pode acontecer por meio de pequenos gestos ou de grandes ações, mas deve transmitir claramente o que vem em seguida. O contrário também existe: a surpresa, quando o espectador espera que uma atitude seja tomada, mas outra acontece. Esse é um recurso que tem fins específicos, ou seja, precisa ter um propósito, um sentido no contexto, e acontece, por exemplo, para gerar humor, por meio da quebra de expectativa. Ademais, esse princípio pode ser relacionado com a metafunção representacional narrativa, da GDV, por meio dos processos de ação e reação, que expressam o movimento e a direção do olhar do personagem no ato cênico.

7 Devido ao espaço reduzido, serão enfocados apenas os elementos utilizados para a análise da videoanimação que compõe o corpus deste artigo. Para conhecer em detalhes os 12 Princípios da Animação da Disney, conferir Thomas e Johnston (1995) e seus seguidores.

8 No original: "1. Squash and Stretch; 2. Anticipation; 3. Staging; 4. Straight ahead action and Pose to pose; 5. Follow through and Overlapping action; 6. Slow in and Slow out; 7. Arcs; 8. Secondary action; 9. Timing; 10. Exaggeration; 11. Solid drawing; 12. Appeal". 
Conforme Sato (2015) explica, o princípio da Aceleração e desaceleração consiste na representação das formas como um corpo ganha ou perde velocidade, respeitando as leis da física, já que, na natureza, não há seres que se movem integralmente em velocidade constante. Por isso, fatores como atrito, gravidade, limitações estruturais e atmosfera interferem na forma como um corpo se movimenta. A relação deste princípio com a GDV vai depender da sequência cênica que forma o ato semiótico. O princípio da Ação secundária corresponde a uma ação subsidiária que complementa uma ação principal, dando mais força cênica a ela. Não é consequência da ação principal, mas uma ação independente, do mesmo corpo ou de outros elementos da cena, que complementam o sentido da ação principal, criando camadas de interpretação e significação, sem tirar o foco da ação principal, enriquecendo-a de forma sutil. A dificuldade nessa composição consiste em equilibrar as duas ações, pois, se houver ênfase demais na secundária, a principal fica apagada, mas se for de menos, ela se torna desnecessária. Por exemplo: a expressão de tristeza (principal) com o enxugar de uma lágrima (secundária), deve ser desenhada de tal modo que o movimento da mão não seja exagerado ou a mão grande demais, cobrindo o rosto. Esse princípio pode ser relacionado à metafunção narrativa de circunstância da GDV. Conforme explicado anteriormente, nesse processo, são utilizados participantes secundários ou ações auxiliares, os quais não entram na estrutura principal do ato semiótico, mas contribuem para adicionar informações. Isso é feito por meio do cenário, de significações subentendidas ou de variados acompanhamentos presentes na cena.

A Sincronia de uma cena baseia-se na relação entre espaço, tempo e ritmo, em uma combinação que determina quando cada pose do movimento deve durar. Em outras palavras, é uma técnica que se preocupa com o número de desenhos ou poses em frames necessários para o estabelecimento da velocidade de ação da animação. De acordo com Sato (2015), esse princípio serve para indicar as qualidades emocionais ou físico-dinâmicas de um personagem, sendo um dos princípios essenciais e, por isso, um dos mais complexos, pois une o personagem à narrativa e à técnica da animação. Assim, para expressar movimentos mais lentos e suaves, são utilizadas mais poses e artes entre elas; e vice-versa: quanto menos poses e artes, mais rápidos e súbitos são os movimentos. Quanto à GDV, esse princípio se aproxima da metafunção representacional, em seu processo narrativo, já que este se refere aos movimentos dos personagens; mas também à modalidade, tendo em vista que essa sincronia pode interferir na identificação das suas características.

O princípio do Exagero em um movimento serve para reforçar expressões ou dar sensação surreal, por exemplo. Assim, a predominância de seu uso pode classificar uma animação como realista (menor o número de exageros) ou cômica (maior o número de exageros). Para a qualidade da animação, os desenhistas procuram o equilíbrio, já que muito exagero sobrecarrega o público com informações, cansando-o e confundindo-o. A aproximação entre esse princípio e a GDV também variará conforme o uso do exagero no contexto da videoanimação. A Solidez do desenho diz respeito à capacidade do animador 
de representar o personagem em qualquer ângulo, demonstrando volume, proporção e profundidade. Esse princípio serve para demonstrar a continuidade da aparência do personagem em movimento, respeitando suas formas e mantendo a dinâmica da ação. Tendo em vista que, na perspectiva da GDV, a metafunção interativa trata das noções de atitude ou perspectiva e dos diferentes ângulos como uma cena e os elementos que a compõem podem ser observados, identifica-se, nesse ponto, a aproximação com o princípio da solidez do desenho.

O Apelo contribui para criar proporções estimulantes ao espectador, distinguir personalidades e dar estilo estético à animação, já que o personagem precisa parecer vivo e interessante (SATO, 2015). Assim como o ator precisa ter carisma, o desenho precisa ter apelo. No mundo Disney, significa qualquer coisa que uma pessoa goste de ver, que tenha charme, design agradável e transmita sentido de modo simples e claro. Isso vale tanto para coelhinhos fofinhos quanto para bruxas malvadas. Assim, um desenho fraco ou um desenho complicado carecem de apelo. É preciso encontrar o equilíbrio, com atitudes simples e diretas, com bons desenhos, já que o uso de muitos efeitos pode ser caro. No mesmo sentido de outros princípios, tendo em vista a sua importância para a estrutura do gênero, o apelo pode se aproximar de qualquer uma das metafunções da GDV, porque envolve a forma como os participantes são representados no ato semiótico.

No que se refere à sonoplastia das animações, Maureen Furniss (2014) salienta que uma das grandes diferenças entre produções amadoras e profissionais é a forma como elas tratam o som. Nesse sentido, como enumera a autora, os recursos sonoros utilizados em uma videoanimação geralmente envolvem três elementos: vozes, efeitos sonoros e músicas. Assim, a voz serve para criar empatia entre espectador e animação, de modo a humanizar a paisagem sonora. Já os ruídos criam uma ilusão de realidade na imagem em movimento, dando sensação de tridimensionalidade, peso e consistência dos objetos desenhados. Por sua vez, a música, que muitas vezes acaba relegada a pano de fundo, tem como função direcionar os sentimentos do espectador, manipulando o seu estado emocional, quase imperceptivelmente, de modo a envolvê-lo com a história da película.

Contudo, nem sempre os personagens falam em uma animação, já que muitas delas optam por transmitir a sua mensagem utilizando apenas canções e sons associados às imagens. Esse recurso acaba tornando o filme mais acessível, já que o espectador não depende de conhecer o idioma dos textos utilizados, compreendendo as relações de sentido por meio das imagens, dos gestos dos personagens e dos sons associados aos objetos e ações. É justamente esse um dos grandes diferenciais das animações: poder ser compreendida apenas por meio das linguagens visual e sonora, sendo, portanto, de compreensão quase universal, para falantes de variadas idades e origens. Nesse sentido, apesar de nem sempre conter falas e textos verbais, de modo geral, as videoanimações quase sempre têm músicas e efeitos sonoros. Como recordam Thomas e Johnston (1995), com o desenvolvimento dessa arte, os animadores começaram a perceber a 
importância dos sons, como o poder da música para atribuir emoção aos desenhos. A seguir, apresentamos uma proposta de análise de uma videoanimação que pretende mostrar o quanto esse arcabouço teórico pode ser produtivo.

\section{Uma análise da videoanimação Menina bonita do laço de fita}

Dirigida por Diego Lopes e Claudio Bitencourt, a videoanimação Menina bonita do laço de fita foi produzida em 2014, pela Oger Sepol Produções, de Curitiba (Paraná). Com duração de 7 minutos e 21 segundos, o curta foi baseado no livro homônimo de Ana Maria Machado (1986) e narra a história de um coelho branco que quer ficar negro, como a menina bonita do laço de fita. O vídeo começa com a filha do coelho perguntando por que ela é tão pretinha. Ele, então, conta para a família a história da menina bonita e de como ele queria descobrir por que ela era tão pretinha. A menina apresenta três sugestões, que logo são seguidas pelo coelho: ter caído em um balde com tinta preta, ter tomado muito café e ter comido muita jabuticaba. Ele, então, segue o que ela disse, mas depois de frustradas tentativas, ouve da mãe da menina bonita que ela é pretinha por causa de artes de uma vó preta que ela tinha. E, assim, o coelho descobre que ser negro é uma condição genética hereditária e não algo que se possa adquirir, ou seja, só se pode nascer negro, não se pode tornar-se negro. Para resolver a situação, ele se casa com uma coelha negra e tem uma filha da mesma cor. A videoanimação termina com a chegada da menina bonita à sala onde está a família de coelhos e com um abraço entre ela e a coelhinha negra, que é sua afilhada.

Menina... (2014) é uma videoanimação que permite levar para a sala de aula a discussão sobre diferentes assuntos e de modo interdisciplinar, de acordo com a faixa etária dos alunos. A proposta de análise que ora realizamos considera um trabalho que se pode fazer com alunos dos anos iniciais do segundo ciclo do Ensino Fundamental, a fim de motivar uma conversa sobre temas como identidade negra e combate ao racismo, bem como um trabalho sobre textos literários transpostos para outros gêneros e mídias e sobre relações de intertextualidade. Pode-se, ainda, estabelecer um diálogo com a disciplina de ciências, para abordar questões sobre hereditariedade e árvore genealógica.

Tendo em vista a limitação de espaço do artigo, nosso enfoque se voltou apenas à descrição das linguagens que compõem a videoanimação ${ }^{9}$. Ressaltamos que há outros caminhos de análise e que faremos um recorte dos aspectos que consideramos mais pertinentes à discussão pretendida. Por isso também, os temas mencionados são uma

9 O uso das imagens retiradas da videoanimação (MENINA..., 2014) teve, exclusivamente, objetivos educacionais, sem fins lucrativos, podendo, portanto, enquadrar-se na política de usos aceitáveis (YOUTUBE, 2020) das mídias para a formação cidadã. Garante-se, dessa forma, o Direito à Comunicação, em um processo educativo que forme pessoas mais autônomas, "sujeitos da comunicação, cidadãos e cidadãs que se expressam no espaço público" (BRASIL, 2009, p. 10). 
sugestão para ampliar o trabalho com essa videoanimação em sala de aula, tomando-se o gênero como instrumento para o ensino, e não como objeto de estudo em si. Nós nos baseamos na GDV (KRESS; VAN LEEUWEN, 2006), nos 12 Princípios da Animação da Disney (THOMAS; JOHNSTON, 1995) e no referencial sobre sonoplastia em animações (FURNISS, 2014), a fim de se demonstrar como esses aportes podem ser combinados e inter-relacionados para a análise dos efeitos de sentido provocados pela linguagem do gênero videoanimação e como esse projeto de dizer dos criadores do curta permite discutir questões sobre temas como identidade e representatividade. Dessa forma, passa-se à análise ${ }^{10}$.

Como participantes da videoanimação temos, como PI, os diretores, a produtora e a equipe que elaborou o vídeo, bem como todas as pessoas que podem assisti-lo por meio da plataforma on-line de vídeos onde ele está disponível. Já os PR são a família de coelhos, a menina bonita do laço de fita, a mãe da menina, a sala da família de coelhos, o quintal da menina bonita, a casa, a rede, o livro, a árvore, o balde de tinta, a chuva, o café, as jabuticabas etc. A metafunção representacional é utilizada, para começar, pela forma como os PR principais são caracterizados: o coelho e a menina são representados como "fofinhos", com traços simpáticos e da forma como tradicionalmente se imagina um coelho (branco, dentuço, com orelhas grandes e rosas). Já a menina tem um grande laço vermelho na cabeça, a fim de evidenciar que ela é a "menina bonita do laço de fita", como indica o título da videoanimação. E ela é negra, característica que motiva a pergunta do coelho e serve como fio condutor para a história. Essa representação se relaciona com os princípios do Apelo, já que a fofura dos personagens busca criar empatia com o Pl; e do Exagero, já que o laço na cabeça da menina tem tamanho exagerado.

O fato de a cor negra ser associada à beleza e ser motivo de tanta admiração por parte do coelho (a identificação é tamanha que ele deseja tornar-se negro) pode sugerir uma reflexão importante acerca de estereótipos e preconceitos racistas e, ao mesmo tempo, de aceitação. Além disso, a "menina bonita do laço de fita" se impõe na narrativa como padrão de beleza, e as crianças negras poderão se sentir representadas. O laço de fita "exagerado" poderia ser relacionado a um símbolo de empoderamento, que distingue positivamente a menina negra. No que se refere aos processos narrativos, os de reação predominam no curta, já que as intenções dos PR são transmitidas por meio dos olhares. Assim, eles são utilizados, por exemplo, nos momentos em que a menina diz ao coelho como ela ficou pretinha, já que, de acordo com as sequências das cenas, ela olha, depois da primeira pergunta, para o livro e, depois da terceira pergunta, para o pé de jabuticaba, para ter ideia de como responder-Ihe, conforme Figura 2. Essas cenas exemplificam o processo narrativo de reação, em que a menina é a reatora, que reage aos fenômenos

10 Destacamos que os recortes estáticos das cenas dificultam a compreensão dos sentidos que decorrem das imagens em movimento, a característica principal de uma animação. Por isso, recomendamos que os leitores assistam ao vídeo, a fim de compreenderem de modo mais evidente o que pretendemos analisar. 
que olha: o livro e o pé de jabuticaba. Como estes aparecem na cena ao mesmo tempo que ela, há um processo de reação transacional. Os processos de ação aparecem, por exemplo, quando o coelho (ator) segura a xícara (meta), para beber o café, e pega o espelho (meta), para ver se ficou pretinho como a menina bonita.

Figura 2. Exemplos de processo narrativo de reação transacional

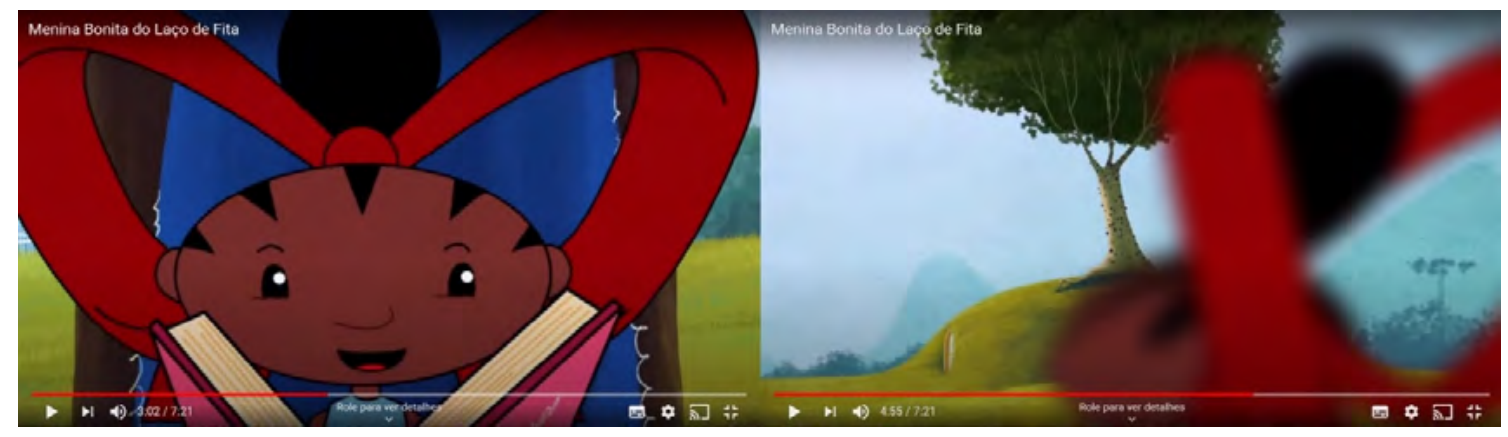

Fonte: cenas aos 3:02 e aos 4:55 da videoanimação Menina... (2014)

A cena da menina com o livro (Figura 2) ainda é um exemplo do princípio da Antecipação, já que a menina fala "huuum", enquanto está pensando em como responder ao coelho, o que é seguido pela fala "aaaah", quando ela vê as latas de tinta no livro e encontra uma resposta. Essas duas interjeições criam uma expectativa no PI, em relação ao que vai acontecer em seguida. A circunstância de significação da GDV também aparece nessa cena, já que, na imagem do livro, dois baldes com as cores das combinações (azul + vermelho e amarelo + vermelho) são utilizados com as cores roxa e laranja, em vez do nome da cor.

A metafunção representacional ainda é utilizada, por meio de um processo mental, quando o coelho recorda tudo o que fez para tentar ficar pretinho, conforme Figura 3. Essa noção é transmitida por meio de um balão de pensamento (linha curva imitando nuvem e ponta direcional com bolinhas), que surge quando o coelho olha para cima. Por isso, essa sequência de cenas é também um exemplo do uso da metafunção composicional a qual, como explicamos anteriormente, integra os significados das metafunções representacional e interativa. O valor informacional real vs. ideal é exemplificado por meio dessa cena, já que o coelho está na parte inferior da imagem, no campo do concreto, enquanto a lembrança surge na parte superior, o campo do ideal, do abstrato. Conforme referencial apresentado na seção anterior, a sonoplastia é importante para complementar o sentido dessas imagens, como no momento da lembrança, que é acompanhado por um efeito sonoro que remete ao som de uma harpa. 
Figura 3. Exemplos de processo mental e valor informacional real vs. ideal

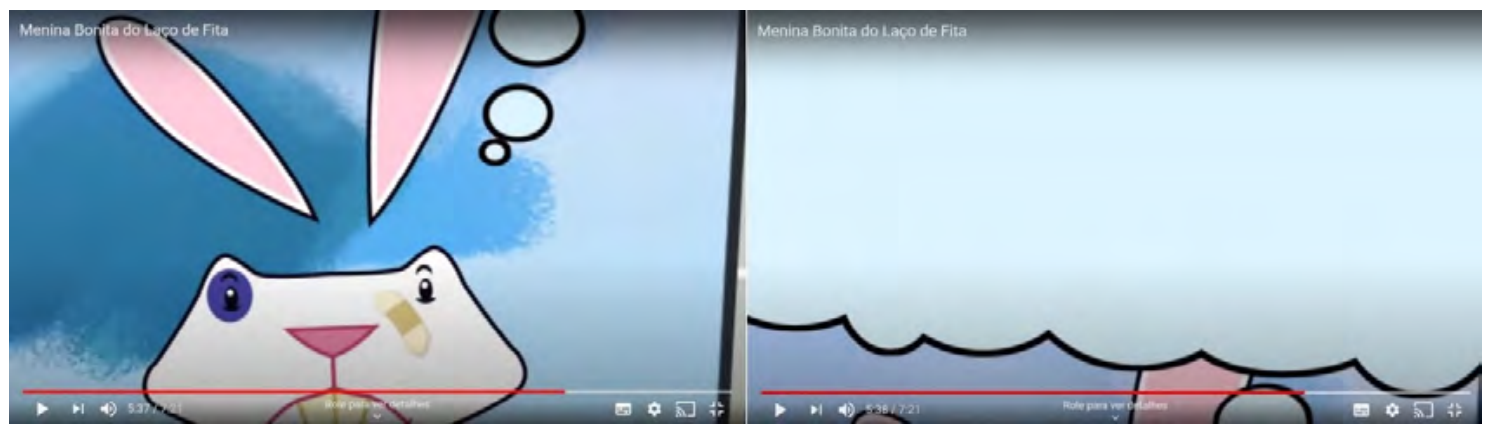

Fonte: cenas aos 5:37 e aos 5:38 da videoanimação Menina... (2014)

As interações entre PR e Pl, analisadas por meio da metafunção interativa, manifestamse por meio do olhar que, em Menina... (2014), é predominantemente de oferta/ exposição, já que os PR são objeto do olhar do PI. Há, no entanto, momentos de contato de demanda/interpelação, em que o PR olha para o PI, como quando o coelho está na janela e cumprimenta a menina ou quando começa a contar a história, conforme Figura 4. O contexto permite observar que ele, na verdade, está olhando para a menina e para os filhos, respectivamente, mas esse sentido é transmitido pelo olhar do coelho para o espectador, como se este assumisse o lugar dos interlocutores do animal. Nessas cenas é possível ver, ainda, o efeito sonoro de um som chiado emitido pelo PR, comumente atribuído a coelhos em desenhos animados.

Figura 4. Exemplo de olhar de demanda/interpelação

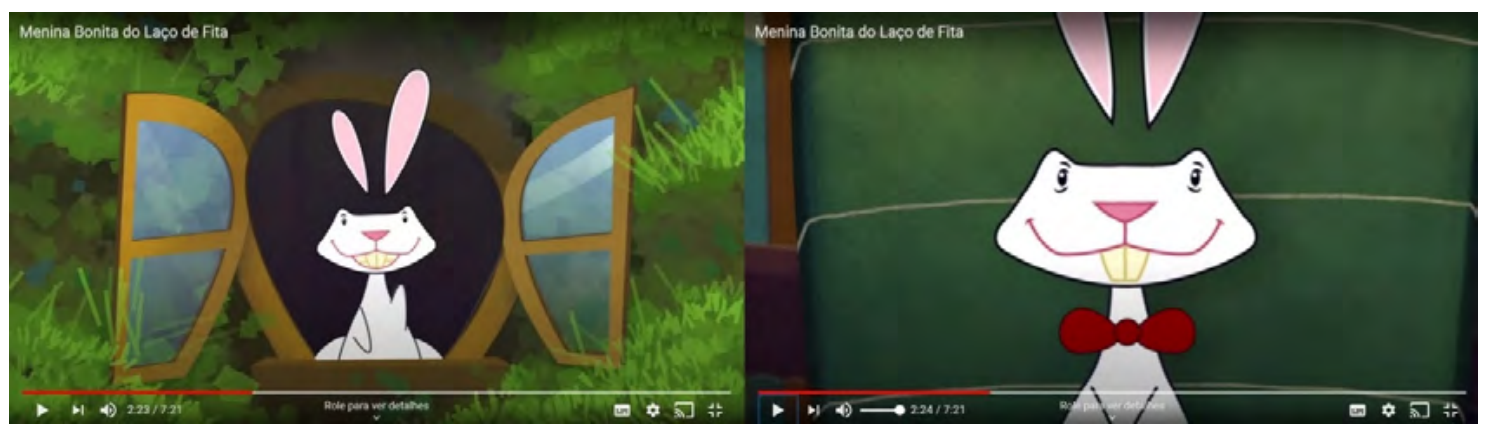

Fonte: cenas aos 2:23 e aos 2:24 da videoanimação Menina... (2014)

Esse elemento sonoro, associado aos elementos visuais, contribui para a representação esperada de um coelho e, por conseguinte, aos efeitos de sentido pretendidos pela videoanimação. Temos, ainda no que se refere ao som que o coelho faz com o dentinho, um exemplo do que a GDV chama de circunstância de significação e os 12 Princípios da Animação identificam como Ação secundária, já que se trata de uma atitude independente, mas que contribui para as ações e a caracterização do personagem. 0 mesmo vale para a forma como ele mexe o nariz. 
Analisando o enquadramento, é possível ver que há uma predominância de plano médio, com utilização do plano fechado para evidenciar, por exemplo, o olhar da menina para o livro (Figura 2), ou os machucados do coelho, em decorrência de sucessivas tentativas frustradas de se tornar negro (Figura 3). Já o plano geral é utilizado, por exemplo, nos momentos em que o coelho vai até a menina para perguntar: "qual é o teu segredo pra ser assim tão pretinha" (MENINA..., 2014), evidenciando o movimento ligeiro do coelho, ao deixar um rastro branco, conforme Figura 5. Essa representação do movimento do coelho exemplifica, também, o princípio da Aceleração e desaceleração. Ainda no que se refere à recorrente pergunta do coelho, ela funciona como um elemento de coesão textual, já que serve como um fio condutor para a narrativa. Ela se repete três vezes, sendo sempre antecedida por uma pequena melodia, o que também serve para criar expectativa no Pl, de acordo com o princípio da Antecipação.

Figura 5. Exemplos de enquadramento em plano geral e da representação do movimento do coelho

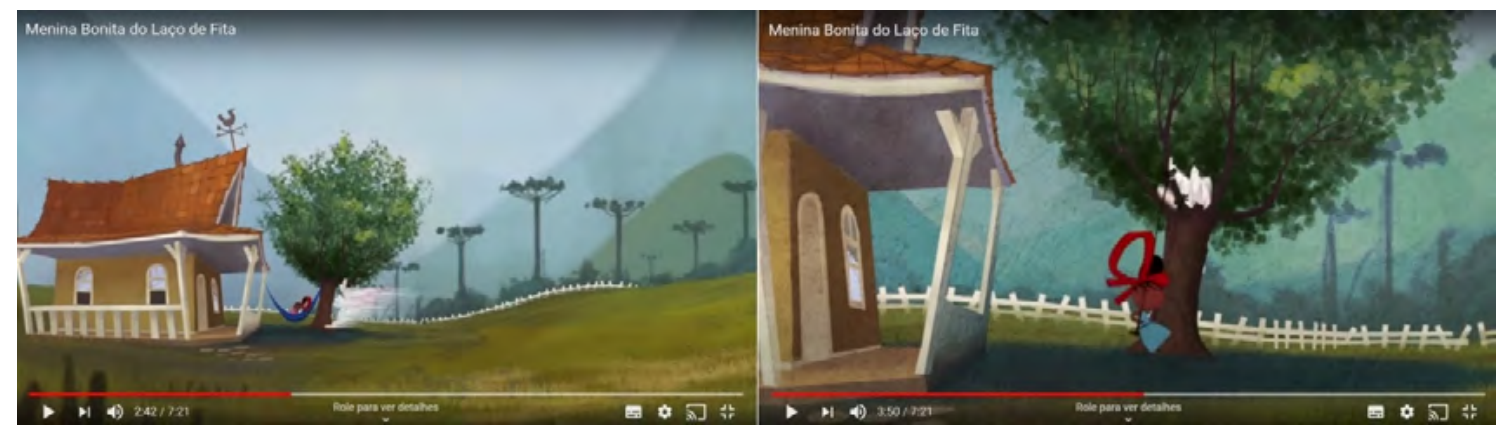

Fonte: cenas aos 2:42 e aos 3:50 da videoanimação Menina... (2014)

Também no campo da metafunção interativa, o uso da perspectiva subjetiva oblíqua vertical em ângulo alto pode ser exemplificado pelo momento em que o coelho perde a cor preta, por causa da chuva, criando um efeito como se ela o olhasse de cima, exercendo um poder sobre ele. Esse uso, associado ao zoom, cria uma sensação de pequenez e impotência do coelho em relação à chuva, conforme Figura 6. Além disso, a cena é complementada por uma música de suspense e pelos efeitos sonoros da chuva, com os trovões e as gotas caindo. Já a perspectiva objetiva é a que predomina na maior parte da videoanimação, como podemos ver na Figura 5. A variação de perspectivas também serve para demonstrar o uso do princípio da Solidez do desenho, já que a forma do coelho é coerente com o esperado, de acordo com o ângulo em que ele é visto. 
Figura 6. Sequência de cenas que exemplifica a perspectiva subjetiva associada ao zoom

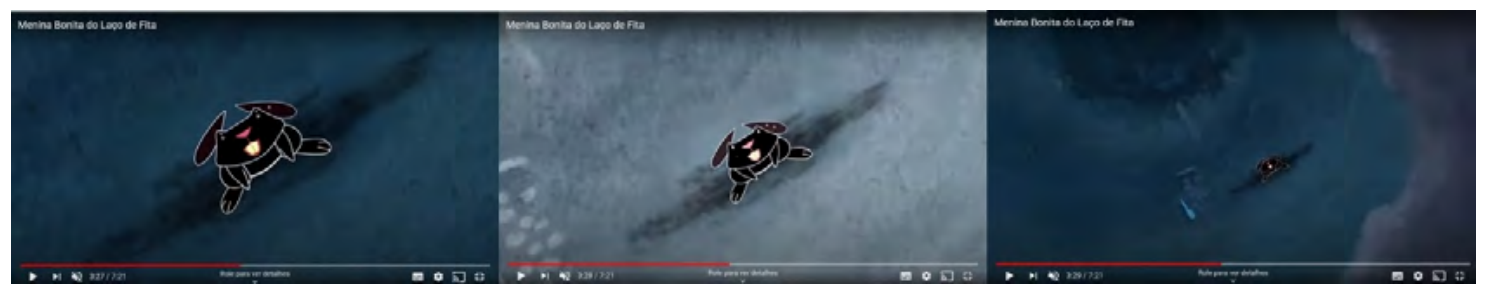

Fonte: cenas aos 3:27, 3:28 e 3:29 da videoanimação Menina... (2014)

No que se refere à modalidade, é possível notar uma representação mais realística das imagens, mas como se fosse um desenho de criança, com formas planas para compor uma animação em duas dimensões. Isso também confere Apelo à videoanimação, conforme mencionamos anteriormente. Além disso, são utilizadas muitas cores para indicar quando é dia (Figuras 2 e 5) e tons de azul para indicar quando é noite ou o tempo está fechado, por causa da chuva (Figura 6). A representação do movimento do coelho, como uma mancha borrada, também é um exemplo do uso da modalidade que, nesse caso, está associada aos princípios da Aceleração e desaceleração, porque o borrão serve para indicar o movimento, da Sincronia, já que indica a duração e a velocidade do movimento, e do Exagero, pois reforça a expressão do movimento.

Quanto à metafunção composicional, a saliência pode ser exemplificada pela cena da Figura 2, já que o olhar do espectador é direcionado ao pé de jabuticaba, que se mantém em foco, enquanto a menina, em primeiro plano, fica desfocada, o que transmite a ideia de que ela olha para a árvore. Já a moldura é utilizada, por exemplo, quando o coelho está na janela na própria toca, para olhar a menina no quintal (Figura 4), ou quando ele chega à janela da cozinha, para perguntar à menina pela última vez. A janela funciona, então, como uma moldura que dá destaque ao coelho.

Voltando à sonoplastia da videoanimação, além das falas dos PR e dos efeitos sonoros que complementam e potencializam as imagens em movimento, destacamos o uso da música Preta, pretinha. Composta por Luiz Galvão e Moraes Moreira, em 1972, a canção ficou conhecida pela interpretação dos Novos Baianos, grupo de MPB que fez sucesso no Brasil na década de 1970. O refrão da música é utilizado quando o coelho está se pintando de preto. Além de uma relação de intertextualidade, já que há um texto dentro de outro, o uso da música amplia os sentidos propostos pela videoanimação, pois se relaciona com a pergunta feita várias vezes pelo coelho: "menina bonita do laço de fita, qual é o teu segredo pra ser assim tão pretinha" (MENINA..., 2014). O uso do diminutivo "pretinha", na pergunta do coelho e na letra da canção, sugere uma forma carinhosa de tratamento, assume uma conotação positiva dentro do contexto da narrativa, abrindo espaço para um debate, por exemplo, sobre como a própria linguagem pode contribuir para reforçar atitudes racistas ou, pelo contrário, para romper preconceitos arraigados na sociedade. 
A relação entre as linguagens verbal, não verbal e sonora permite compreender os efeitos de sentido da videoanimação e sua análise pode ser utilizada para a leitura desse gênero multimodal e para promover uma discussão sobre diferentes temas. Como mencionado, a análise de Menina... (2014) pode, por exemplo, destacar a forma como o curta valoriza a identidade negra da menina bonita do laço de fita, já que essa característica é tão admirada pelo coelho que ele tenta ficar igual a ela. Logo no início da história ( 1 minuto e 26 segundos), ele diz: "Sempre que eu via a nossa vizinha, eu ficava fascinado com sua cor tão pretinha, tão linda, tão diferente da minha" (MENINA..., 2014). E, em seguida, compara os cabelos negros e enrolados dela aos fiapos da noite e a pele escura e lustrosa ao pelo da pantera negra quando pula na chuva. Podemos notar, nesse momento, que o uso da comparação serve para valorizar a cor da menina.

Justamente por isso, é a cor o elemento principal da história, já que são citados elementos negros como forma de fazer o coelho deixar de ser branco: a tinta, o café, a jabuticaba e a feijoada têm em comum a cor preta, como a da menina. Essa associação positiva com elementos negros pode ser destacada, durante o trabalho com a videoanimação, junto aos alunos, motivando uma discussão sobre outros elementos que podem ser utilizados para a comparação, em detrimento de comparações pejorativas que muitas vezes são utilizadas na sociedade. Além disso, o fato de a menina ser negra porque tem uma mãe e uma avó negras, conforme apresentado na história, pode motivar uma discussão sobre os antepassados dos alunos, por meio da organização de uma árvore genealógica e da produção de biografias, para que eles conheçam as pessoas de sua família. Além disso, a referência à música Preta, pretinha (GALVÃO; MOREIRA, 1972) possibilita uma discussão sobre relações de intertextualidade, ampliando o repertório e o conhecimento de mundo dos alunos. Pode-se, assim, pedir que eles citem outras músicas e textos variados que dialoguem com o curta.

\section{Considerações finais}

A inclusão das tecnologias digitais e dos textos que têm essas ferramentas como suporte são pauta de muitas pesquisas e ganharam ainda mais evidência depois da publicação da BNCC (BRASIL, 2018), a qual se insere em uma contemporaneidade marcada pela quinta revolução tecnológica. As novas formas de sociabilidade e as novas construções culturais conectam pessoas a máquinas e máquinas a máquinas, por meio da tecnologia $5 G$, e a escola não pode estar alheia a essa realidade. Diante disso, é importante que os professores conheçam bem os gêneros multimodais do ambiente virtual, como é o caso da videoanimação, para serem capazes de explorá-los como instrumentos de ensino.

Com base na articulação teórica entre a GDV (KRESS; VAN LEEUWEN, 2006), os 12 Princípios da Animação da Disney (THOMAS; JOHNSTON, 1995) e o estudo da sonoplastia das animações (FURNISS, 2014), pretendemos mostrar que a análise proposta pode contribuir para uma melhor compreensão dos efeitos de sentido criados no curta Menina 
bonita do laço de fita (2014), permitindo pensar em diferentes abordagens no ensinoaprendizagem de língua portuguesa. Assim, pretendemos demonstrar como o gênero videoanimação pode ser utilizado no contexto de ensino para ampliar a capacidade de leitura dos alunos, auxiliando-os a ler, também, o mundo que os cerca, cuja comunicação é cada vez mais permeada por textos digitais.

No caso da animação analisada, entre as temáticas que mais se evidenciam, para o trabalho em sala de aula, estão a identidade negra e o combate ao racismo. Em um planeta que vive momentos de protestos em busca de respeito pela vida e de valorização identitária de grupos marginalizados, a escola não pode se esquivar de sua responsabilidade sociocultural. Nesse sentido, o estigma social, que gera preconceito e discriminação, há tantos séculos, pode ser combatido, ao se discutir sobre representatividade étnico-racial, por meio de textos como Menina bonita do laço de fita (2014), que afirma, positivamente, a identidade negra, conforme demonstrado pela análise.

\section{REFERÊNCIAS}

BRASIL. Ministério da Educação. Base Nacional Comum Curricular (BNCC). Brasília: MEC. 2018. Disponível em: http://basenacionalcomum.mec.gov.br/. Acesso em: 14 fev. 2020.

BRASIL. Ministério da Educação. Secretaria de Educação Continuada. Caderno comunicação e uso de mídias. Brasília: MEC, 2009. (Série Mais Educação). Disponível em: http://portal.mec.gov.br/index.php?option=com_docman\&view=download\&alias $=12328$ comunicacaoeusodemidias-pdf\&ltemid=30192. Acesso em: 14 jun. 2020.

BRITO, R. C. L.; PIMENTA, S. M. de O. A Gramática do Design Visual. In: LIMA, C. H. P.; PIMENTA, S. M. de O.; AZEVEDO, A. M. T. de (org.). Incursões Semióticas: Teoria e Prática de Gramática Sistêmico-Funcional, Multimodalidade, Semiótica Social e Análise Crítica do Discurso. Rio de Janeiro: Livre Expressão, 2009. p. 87-117.

DIONÍSIO, A. P. Multimodalidade discursiva na atividade oral e escrita. In: MARCUSCHI, L. A.; DIONÍSIO, A. P. Fala e escrita. Belo Horizonte: Autêntica, 2007.

FURNISS, M. General concepts: sound and structural design. In: FURNISS, M. Art in motion: animation aesthetics - revised edition. Londres: John Libbey Publishing, 2014. [Edição do Kindle]

GALVÃO, L.; MOREIRA, M. Preta Pretinha. 1972. Música interpretada pelos Novos Baianos. Disponível em: https://www.letras.mus.br/os-novos-baianos/122200/. Acesso em: 19 set. 2020. 
KRESS, G.; VAN LEEUWEN, T. Reading images: the grammar of visual design. 5th. London and New York: Routledge, 2006.

LEAL, A. A. A organização textual do gênero cartoon: aspectos linguísticos e condicionamentos não linguísticos. 2011. Tese (Doutorado em Linguística) - Faculdade de Ciências Sociais e Humanas, Universidade Nova de Lisboa, Lisboa, 2011. Disponível em: http://run.unl.pt/handle/10362/6646. Acesso em: 2 jan. 2020.

MACHADO, A. M. Menina bonita do laço de fita. São Paulo: Ática, 1986.

MENINA bonita do laço de fita. Direção de Diego Lopes e Claudio Bitencourt. Curitiba: Oger Sepol Produções, 2014. (7min e 21s), son., color. Disponível em: https://www. youtube.com/watch?v=UhR8SXhQv6s. Acesso em: 14 jul. 2020.

RIBEIRO, D. Pequeno manual antirracista. São Paulo: Companhia das Letras, 2019. [Edição do Kindle]

ROJO, R. Textos multimodais. In: FRADE, I. C. A. da S.; VAL, M. da G. F. da C.; BREGUNCI, M. das G. de C. Glossário Ceale de termos de Alfabetização, leitura e escrita para educadores. Belo Horizonte: CEALE/Faculdade de Educação da UFMG, 2014. Disponível em: http://www.ceale.fae.ufmg.br/app/webroot/glossarioceale/verbetes/textosmultimodais. Acesso em: 25 jun. 2020.

SATO, L. M. Os 12 princípios da animação: da adesão à sua subversão. 2015. Dissertação (Mestrado em Comunicação) - Pontifícia Universidade Católica de São Paulo, São Paulo, 2015. Disponível em: https://tede2.pucsp.br/handle/handle/4756. Acesso em: 7 jul. 2020.

THOMAS, F.; JOHNSTON, O. The illusion of life: Disney animation. Glendale: Disney Editions, 1995.

YOUTUBE (org.). O que é uso aceitável? Disponível em: https://www.youtube.com/intl/ptBR/about/copyright/fair-use/\#yt-copyright-resources. Acesso em: 14 jun. 2020. 